\title{
Use of Health Related Quality of Life in Clinical Trials for Severe Asthma: A Systematic Review
}

\section{Joseph W Lanario Lorna Burns (D)}

Faculty of Health, University of Plymouth, Plymouth, UK
Correspondence: Joseph W Lanario Email joseph.lanario@plymouth.ac.uk
Background: Asthma Health Related Quality of Life (HRQoL) is an outcome important to patients with severe asthma and can provide clinicians with additional insight into the benefits of treatment. The aim of this systematic review is to examine the use and reporting of HRQoL questionnaires within randomised controlled trials (RCTs) of biologics, fevipiprant and bronchial thermoplasty.

Methods: We followed the guidelines on the Preferred Reporting Items for Systematic reviews and Meta-Analysis (PRISMA) statement. Of the 2380 retrieved articles, 52 studies were identified for inclusion.

Results: Sixty-three percent included an asthma HRQoL questionnaire. It was a secondary outcome in the majority of cases $(73 \%)$. The proportion of studies including an asthma HRQoL questionnaire did not change significantly over a 20-year period. While the Asthma Quality of Life Questionnaire (AQLQ) was used in $45 \%$ of studies, $55 \%$ used a variety of 4 questionnaires. Most $(70 \%)$ of the studies that included a HRQoL questionnaire did not report its subscale scores. Approximately half (52\%) of studies that used HRQoL reported this in the abstract of the paper. A higher proportion of studies used an asthma control questionnaire compared to a HRQoL questionnaire (71\% vs $63 \%$ ).

Conclusion: In order to increase the use of asthma HRQoL questionnaires in RCTs of severe asthma treatments, the drivers and barriers to their use must first be understood. At present, the patients' perspective is underrepresented in RCTs of biologics, fevipiprant and bronchial thermoplasty for severe asthma.

Keywords: severe asthma, quality of life, systematic review

\section{Introduction}

Severe asthma is a disease of the airways characterised by high symptom burden and resistance to high levels of treatment (GINA step 4 and 5). ${ }^{1}$ These patients are a small proportion of all asthma sufferers (3-8\%) but experience a disproportionate number of sick days and rely heavily on the health care systems available to them. ${ }^{2-4}$

A recent survey of patients with severe asthma found that improving overall quality of life was the most important outcome for the majority of participants. ${ }^{5}$ This was deemed more important than reducing the number and severity of exacerbations and being able to participate in physical activity. In qualitative studies, patients with severe asthma describe how the disease affects every aspect of their lives. The negative impacts include physical, emotional and interpersonal burdens $^{6}$ that can be associated with asthma symptoms, the side effects of treatment $^{7}$ and the consequences of living with a chronic illness. ${ }^{8}$ 
The importance of patient centred outcomes is emphasised by the Severe Heterogeneous Asthma Research collaboration, Patient-centred (SHARP). Outcomes important to patients have been incorporated into SHARP's research aims because objective measures may not represent the full morbidity of severe asthma and capture individual differences in disease experience. This decision was guided by SHARP's patient co-chairs and patient advisory group. ${ }^{9}$

Unlike objective measures, Health Related Quality of Life (HRQoL) questionnaires provide information on whether a treatment is worthwhile from the patient's perspective, a perspective that includes the burden of disease and the burden of treatment. ${ }^{10}$ In addition, some HRQoL questionnaire items can be divided into subscales which provide greater detail on the area of HRQoL that has changed. For example, the 15 questions that make up the Asthma Quality of Life Questionnaire (AQLQ) can be subdivided into four domains, Activity limitation, Asthma symptoms, Emotional Functional and Environmental exposure. ${ }^{11}$ As such, HRQoL questionnaires need to be used in both clinical practice and trials so that the patient perspective is represented. ${ }^{12}$

As with HRQoL questionnaires, asthma control questionnaires are also completed by patients. However, unlike HRQoL questionnaires, asthma control questionnaires focus on the clinical impairments experienced by patients and are more closely correlated with objective measures such as lung function. ${ }^{13,14}$ In contrast, HRQoL questionnaires are less correlated with measures such as lung function and provide additional information. ${ }^{15}$ While HRQoL questionnaires and asthma control questionnaires both collect data directly from patients, they capture different information about their disease experience.

Since 2013, the National Institute for Clinical and Health Care Excellence (NICE) has approved four novel biologic treatments for severe asthma ${ }^{16-19}$ and a new surgical intervention called bronchial thermoplasty (BT). ${ }^{20}$ The European Respiratory Society/American Thoracic Society (ERS/ATS) guidelines recommend reduction in the number of exacerbations and improvement in lung function as measures of response to treatment in research and clinical practice. ${ }^{1}$ These same guidelines also recommend the use of Patient Reported Outcome Measures (PROMs) such as HRQoL questionnaires and asthma control questionnaires, but do not specify a particular questionnaire. However, the validity of generic HRQoL or health status questionnaires for asthma patients has been criticised $^{21,22}$ and asthma-specific HRQoL questionnaires are therefore preferred.
A problem faced by authors of guidelines who may wish to recommend a HRQoL measure is that the available questionnaires have been criticised in recent years. An appraisal conducted in 2011 identified eight HRQoL questionnaires for adults with asthma. The authors did not raise any major concerns with the statistical properties of these questionnaires but did criticise their content as being more likely to assess asthma symptom control rather than patient's quality of life because of their experiences with asthma. ${ }^{23}$ The authors concluded that the asthma HRQoL questionnaires available at the time of their appraisal were best suited as secondary outcomes.

Similarly, in a qualitative study patients commented that Juniper's Asthma Quality of Life Questionnaire (AQLQ) ${ }^{11}$ was overly medical and too focused on symptom burden rather than HRQoL burden. ${ }^{24}$ When presented with the Living With Asthma Questionnaire (LWAQ) ${ }^{25}$ and the Sydney Asthma Quality of Life Questionnaire (SydneyAQLQ ${ }^{26}$ patients described these two questionnaires as non-medical and preferred either to Juniper's AQLQ.

A qualitative study that recruited patients with severe asthma found that the concerns of this patient group were not reflected in eight asthma HRQoL questionnaires. The authors suggested that this is because the questionnaires were validated for use with mild/moderate asthma patients and do not ask all of the questions relevant to a severe population, eg, the impact of frequent exacerbations or medication side effects on HRQoL. ${ }^{10}$

Use of HRQoL questionnaires and the subsequent reporting of their data are needed to fully understand the impacts of severe asthma on patients' lives and the wider benefits offered by a treatment beyond its clinical efficacy. However, it is possible that researchers are discouraged from including a HRQoL questionnaire in their RCTs due to concerns about their content validity. Published work from other disease areas suggests that HRQoL is poorly reported, despite CONSORT reporting guidelines. ${ }^{27,28}$ It is not known whether the quality of reporting is adequate in the case RCTs of biologics, fevipiprant and bronchial thermoplasty (BT) for adults with severe asthma.

\section{Aims}

The aim of this systematic review is to examine the use and reporting of HRQoL in published RCTs of biologics, fevipiprant and BT for severe asthma. The objectives are first to determine how often HRQoL questionnaires were used as an outcome in these studies. Second, if a HRQoL questionnaire was used, to determine if it was a primary, 
secondary or exploratory outcome. Third, to determine the names of the asthma HRQoL questionnaires used. Fourth, to assess how thoroughly their data were reported. Fifth, to determine how often asthma control questionnaires were used in these studies.

\section{Methods}

\section{Protocol and Registration}

The review protocol is registered on the international prospective register of systematic reviews PROSPERO (CRD42019137899).

\section{Eligibility Criteria}

Published reports of randomised controlled trials were eligible for inclusion if they studied effects of treatments for severe asthma, including any dosage or administration of biologic treatments, fevipiprant or bronchial thermoplasty. We included interventions that are both licensed and unlicensed for use in the UK or US. Studies using research methodology other than that of a randomised controlled trial (eg, open label observational studies) were excluded. Publications concerning sub-analyses of the main data set (eg, only the UK participants) or post hoc analyses were also excluded.

Studies conducted with only a paediatric population were excluded, but studies which had both a paediatric and adult populations were included (eg, age range of 12 75 years).

\section{Information Sources}

Five healthcare databases were searched for published studies: Embase, MEDLINE, CENTRAL, Scopus and CINAHL. An information specialist (LB) conducted the searches on $06 / 11 / 20$. The purpose of this review was to assess the quality of reporting in published studies; therefore, unpublished studies were not sought. The references and citations of published systematic reviews were checked for further studies.

\section{Search}

The search strategy comprised subject headings and title abstract terms for the following concepts: severe asthma, named treatments for severe asthma and the SIGN search filter for randomised controlled trials. ${ }^{29}$ An English language limit was applied. No date limit was used. The full search strategies are given in the Appendix.

\section{Study Selection}

The authors first independently double screened the title and abstract of the search results using the Rayyan web application.

\section{Data Collection Process}

A pilot search was initially conducted to test the screening criteria and data extraction processes. Next, the first 50 results were screened and underwent data extraction by the two authors. This was carried out independently using an Excel spreadsheet. A sample of $10 \%$ of the studies was used to assess interrater reliability and to refine the wording of the data extraction questions if one researcher's interpretation of a data extraction question was different to the other. Trial registries were used to locate study protocols and to identify reports of the same study, which were later linked together to be treated as one unit of analysis.

\section{Data Items}

The following data items were extracted: Name of the study or name of first author of the paper; protocol location or registry number (eg, NCT number); number of papers making up the unit of analysis; date of first publication; age range of participants included in the study; whether a HRQoL questionnaire was mentioned in the protocol (if so, was this designated as a primary, secondary or exploratory outcome); name of the severe asthma treatment studied; whether a HRQoL questionnaire was included in the paper (if so, was this reported as a primary, secondary or exploratory outcome); whether HRQoL questionnaire data were reported in the abstract; whether the HRQoL questionnaire data were reported in the main body of the paper or in the online supplement; the name of the HRQoL measure used; whether the subscale scores of the HRQoL measure were reported; whether an asthma control questionnaire was included in the study (If so, which asthma control questionnaire was used).

\section{Quality of Reporting of HRQoL}

In studies, which used HRQoL, we assessed the quality of reporting using three markers: the reporting of the HRQoL score before and after the intervention; the reporting of a measure of distribution and the reporting of a significance test to compare the HRQoL scores between the intervention and placebo/control group. Ten percent of these data were also assessed for interrater reliability using the method that is described earlier. Questions were refined if necessary. 
There is a known publication bias in scientific literature that favours significant results over non-significant results. ${ }^{30}$ Therefore, we also recorded whether a test of significance on HRQoL data between the treatment and the control groups at follow-up was positive or not.

\section{Results}

\section{Study Selection}

A search of the databases identified 2380 records with an additional 88 records identified through citation searching. The total number of records reduced to 1253 when duplicates were removed. A further 1142 records were excluded after title and abstract screening. The remaining 111 records underwent full text screening and a further 53 were excluded. See Figure 1 for the PRISMA flow diagram.

The remaining 58 papers were identified as eligible for inclusion in the review. These papers concerned 52 separate studies (see Table 1). The mean number of papers per study was 1.19. These papers underwent data extraction.

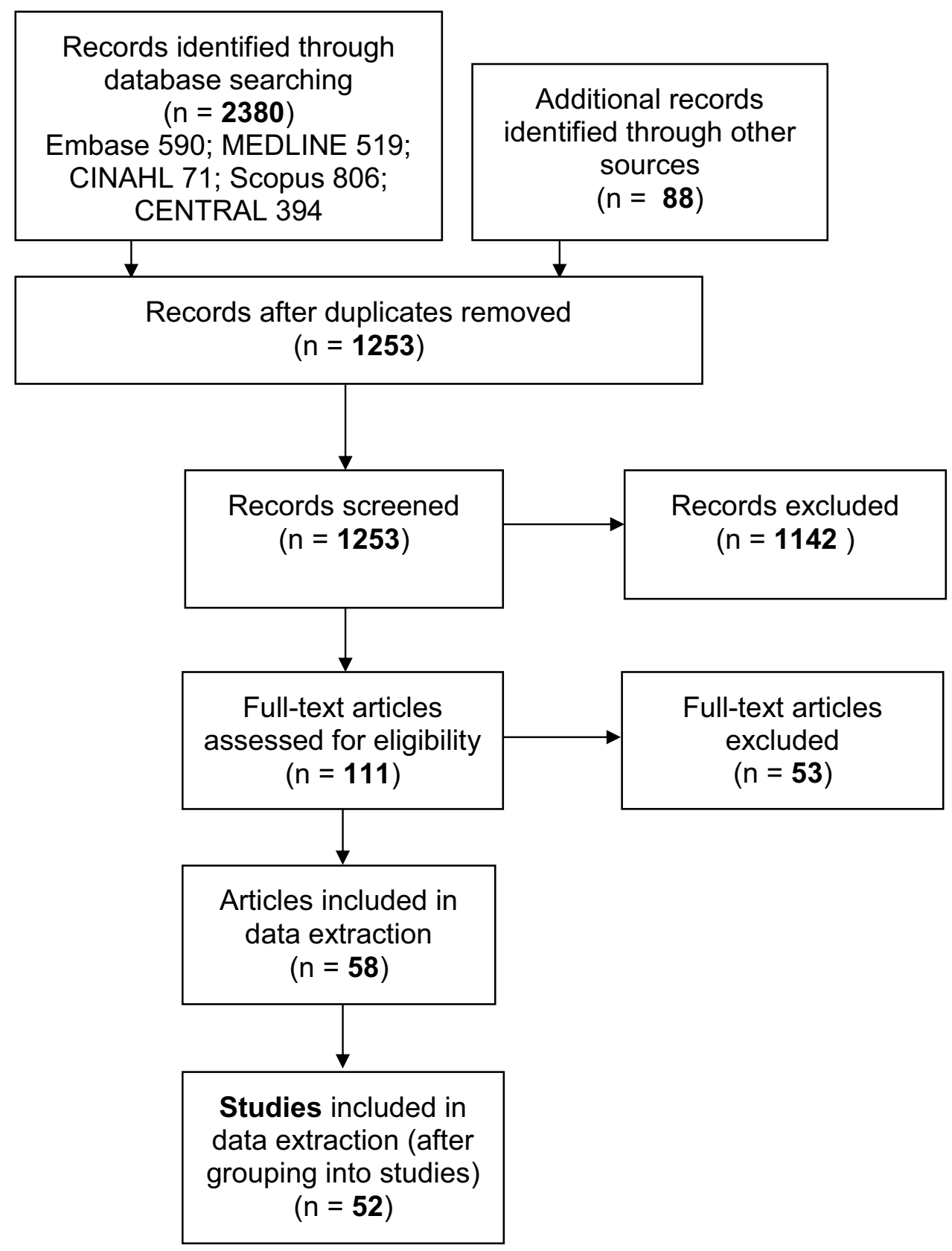

Figure I Search results and study selection. 
Table I Included Papers and Corresponding Studies in Alphabetical Order

\begin{tabular}{|c|c|}
\hline Included Papers ( $n=58)$ & Study Reported (52 Studies) \\
\hline Austin, $2020^{36}$ & CLAVIER; NCT02099656 \\
\hline Ayars, $2013^{37}$ & Nair, 2009; NCT00292877 \\
\hline Ayres, $2004^{38}$ & Ayers, 2004 \\
\hline Bel, $2014^{39}$ & SIRIUS; NCT0I69I508 \\
\hline Bernstein, $2020^{40}$ & $\begin{array}{l}\text { Bernstein, 2020; NCT02452190; } \\
\text { NCT02501629 }\end{array}$ \\
\hline Bjermer, $2016^{41}$ & Bjermer, 20I6; NCT0I270464 \\
\hline Bleecker, $2016^{42}$ & SIROCCO; NCTOI92877I \\
\hline Bousquet, $2011^{43}$ & Bousquet, 201I \\
\hline Brightling, $2015^{44}$ & Brightling, 2015; NCT01402986 \\
\hline Brightling, $2020^{45}$ & $\begin{array}{l}\text { Luster I and 2; NCT02555683; } \\
\text { NCT02563067 }\end{array}$ \\
\hline Buhl, $2002^{46}$ & Soler, 200I \\
\hline Buhl, $2002^{47}$ & Soler, 2001 \\
\hline Busse, $2001^{48}$ & Busse, 2001 \\
\hline Busse, $2019^{49}$ & BORA; NCT02258542 \\
\hline Busse, $2019^{50}$ & TROPOS; NCT02281357 \\
\hline Castro, $2010^{51}$ & AIR 2; NCT0023III 4 \\
\hline Castro, $2011^{52}$ & Castro, 2011 \\
\hline Castro, $2014^{53}$ & Castro, 20I4; NCT0I23886I \\
\hline Castro, $2015^{54}$ & Castro, 2015; NCTOI 287039; NCT01285323; \\
\hline Chanez, $2010^{55}$ & Chanez, 20I0; NCT0045405I \\
\hline Chupp, $2017^{56}$ & MUSCA; NCT02281318 \\
\hline Corren, 2011 ${ }^{57}$ & MILLY; NCT00930I63 \\
\hline Corren, $2016^{58}$ & Corrren, 2016; NCT0I508936 \\
\hline Corren, $2017^{59}$ & Corren, 2017; NCT02054I30 \\
\hline Cox, $2007^{60}$ & AIR I; NCT002I4526 \\
\hline Finn, $2003^{61}$ & Busse, 2001 \\
\hline FitzGerald, $2016^{62}$ & CALIMA; NCT01914757 \\
\hline Garcia, $2013^{63}$ & Garcia, 2013; NCT01007I49 \\
\hline Gonem, $2016^{64}$ & Gonem, 2016; NCT01545726 \\
\hline $\begin{array}{l}\text { Goorsenberg \& Hooghe, } \\
2020^{65}\end{array}$ & TASMA; NCT02225392 \\
\hline Gottlow, $2019^{66}$ & $\begin{array}{l}\text { STRATOS I and 2; NCT0216I757; } \\
\text { NCT02194699 }\end{array}$ \\
\hline
\end{tabular}

(Continued)
Table I (Continued).

\begin{tabular}{|c|c|}
\hline Included Papers $(n=58)$ & Study Reported (52 Studies) \\
\hline Haldar, $2009^{67}$ & Haldar, 2009; ISRCTN75169762 \\
\hline Hall, $2020^{68}$ & Hall, 2020; NCT01832363 \\
\hline Hanania, $2011^{69}$ & EXTRA; NCT003।4574 (corrected number) \\
\hline Holgate, $2004^{70}$ & Holgate, 2004 \\
\hline Hoshino, $2012^{71}$ & Hoshino, 2012 \\
\hline Humbert, $2005^{72}$ & INNOVATE \\
\hline Lanier, $2003^{73}$ & Lanier, 2003 \\
\hline Ledford, $2017^{74}$ & XPORT; NCTOI I 25748 \\
\hline $\mathrm{Li}, 2016^{75}$ & Li, 2016; NCTOI 202903 \\
\hline Mukherjee, $2019^{76}$ & Mukherjee, 2019; NCT02049294 \\
\hline Nair, $2017^{77}$ & ZONDA; NCT02075255 \\
\hline Ohta, $2009^{78}$ & Ohta, 2009 \\
\hline Ohta, $2018^{79}$ & CALIMA; NCTOI914757 \\
\hline Ortega, $2014^{80}$ & MENSA; NCTO169152I \\
\hline Panettieri, $2018^{81}$ & $\begin{array}{l}\text { STRATOS I and 2; NCT02161757; } \\
\text { NCT02 I94699; }\end{array}$ \\
\hline Panettieri, $2020^{82}$ & SOLANA; NCT02869438 \\
\hline Pasha, $2014^{83}$ & Pasha, 2014; NCT00139152 \\
\hline Pavord, $2007^{84}$ & RISA; NCT00214539 \\
\hline Pavord, $2012^{85}$ & DREAM; NCT01000506 \\
\hline Piper, $2013^{86}$ & Piper, 2013; NCT00873860 \\
\hline Rubin, $2012^{87}$ & QUALITX \\
\hline Russell, $2018^{88}$ & MESOS; NCT02449473 \\
\hline Sakamoto, $2020^{89}$ & Sakamoto, 2020; NCT01913028 \\
\hline Soler, $2001^{90}$ & Soler, 2001 \\
\hline Sthoeger, $2007^{91}$ & INNOVATE \\
\hline Vignola, $2004^{92}$ & SOLAR \\
\hline Zeitlin, $2018^{93}$ & ALIZE; NCT028I4643 \\
\hline
\end{tabular}

\section{Study Characteristics}

The studies were published from 2001 onwards with an increasing number of papers published each year. Omalizumab was the most common intervention being trialled, included in $18(35 \%)$ of the studies. The characteristics of the included studies are summarised in Table 2. 
Table 2 Characteristics of Included Studies $(N=52)$

\begin{tabular}{|l|l|}
\hline Severe Asthma Treatment Trialled & n (\%) \\
\hline Omalizumb & $18(35)$ \\
Benralizumab & $7(14)$ \\
Mepolizumab & $6(12)$ \\
Tralokinumab & $5(10)$ \\
Reslizumab & $5(10)$ \\
Bronchial Thermoplasty & $5(10)$ \\
Lebrikuzumab & $2(4)$ \\
Tezepelumab & $2(4)$ \\
Fevipiprant & $2(4)$ \\
\hline Year published & \multicolumn{2}{|l}{} \\
\hline 200I-2005 & $7(14)$ \\
$2006-2010$ & $7(14)$ \\
$2011-2015$ & $14(27)$ \\
$2016-2020$ & $24(46)$ \\
\hline
\end{tabular}

\section{Inclusion of HRQoL Questionnaires in Study Protocols}

Out of the 52 included studies, 41 (79\%) study protocols were found and $11(21 \%)$ were not. Twenty-seven (68\%) of these protocols included an asthma HRQoL measure as an outcome; $3(11 \%)$ as a primary outcome, $21(78 \%)$ as a secondary outcome and $3(11 \%)$ as an exploratory outcome. The remaining 14 (27\%) study protocols did not include an asthma HRQoL measure as an outcome.

Of the three studies that listed HRQoL as an exploratory outcome in the protocol, one did not report this data in the published paper or supplementary material.

\section{Reporting of HRQoL Questionnaires in Published Papers}

Of the 52 studies, $33(63 \%)$ included a HRQoL questionnaire as an outcome; $6(18 \%)$ as a primary outcome, 25
(76\%) as a secondary outcome and $2(6 \%)$ as an exploratory outcome. Nineteen $(37 \%)$ of the studies did not include HRQoL as an outcome. Ten (30\%) of these 33 studies reported the subscale scores of the HRQoL questionnaire, and $23(70 \%)$ did not.

The majority of studies that collected HRQoL data reported this in the main paper rather than the supplementary material of the reviewed papers ( $99 \%$ vs $1 \%)$. See Figure 2 for details on how many studies reported asthma HRQoL and if this data was reported in the studies supplementary material, main paper or abstract of the reviewed papers.

Fifteen of the 33 studies (45\%) that measured HRQoL used the AQLQ, 8 (24\%) used the AQLQ +12, 6 (18\%) used the AQLQ (S) and 4 (12\%) used the St George's Respiratory Questionnaire (SGRQ).

There were some small non-significant fluctuations in the percentage of studies that included a HRQoL questionnaire as an outcome over time (71\% in 2001-2005, $57 \%$ in $2006-2010$, $57 \%$ in $2011-2015$, and $67 \%$ in 2016 2020). Table 3 provides details on which specific measures of HRQoL were used in these studies.

\section{Quality of Reporting of HRQoL Data}

Of the 33 studies that measured HRQoL, 24 (73\%) reported the mean HRQoL scores before and after the intervention in the research publication, including an indication of distribution (eg, standard deviation) and reported a test of significance comparing the intervention and comparison groups at follow up.

Five $(15 \%)$ of the 33 studies reported the mean HRQoL score before and after the intervention and reported a test of significance but not an indication of distribution.

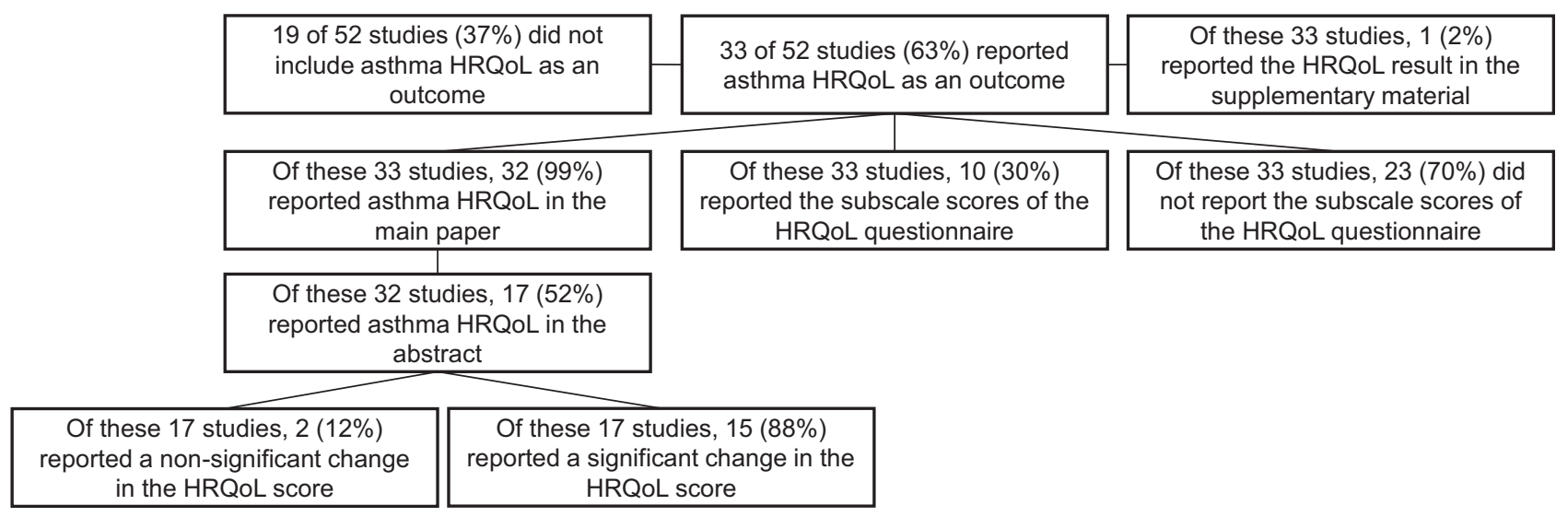

Figure 2 Number and proportion (\%) of studies reporting of asthma HRQoL questionnaires and where this data is reported. 
Table 3 Number and Proportion (\%) of the Specific HRQoL Measures Used by Studies That Included a Measure of HRQoL

\begin{tabular}{|l|l|l|l|l|}
\hline & 200I-2005 (n= 5) & 2006-20I0 (n= 4) & 20II-20I5 (n= 8) & 20I6-2020 (n= I6) \\
\hline SGRQ $_{a}$ & 0 & 0 & $2(25 \%)$ & $2(12.5)$ \\
AQLQ $_{b}$ & $5(100)$ & $4(100)$ & $3(38)$ & $3(19)$ \\
AQLQ $(S)_{c}$ & 0 & 0 & $3(38)$ & $3(19)$ \\
AQLQ $+12_{d}$ & N/A & 0 & 0 & $8(50)$ \\
\hline
\end{tabular}

Note: Year validated: a 1992, ${ }_{b} 1993,{ }_{c} 1999,{ }_{d} 2005$.

Four $(12 \%)$ of the 33 studies reported the mean HRQoL scores before and after the intervention and their distributions, but did not report a test of significance.

Of the 29 studies that reported a test of significance 22 (76\%) found a significant difference in the mean HRQoL score when comparing the intervention group to the placebo group at follow-up. Seven $(24 \%)$ did not find a significant difference. Fifteen (68\%) of these 22 studies reported this significant result in the abstract and 7 (32\%) did not (see Figure 2).

\section{Use of Asthma Control Questionnaires}

Thirty-seven (71\%) of the included studies reported Asthma Control Questionnaire (ACQ) data. Four of the thirty-seven studies reported an additional asthma control PROM as well as the ACQ. These measures were: the Asthma Control Test (ACT) the Asthma Symptom Utility Index, the Wasserfallen measure of rhino-conjunctivitis and asthma symptoms, and the Asthma Control Daily Diary. One study (2\%) reported Asthma Control Test (ACT) data and no other asthma control PROM. Fourteen studies (27\%) did not report any asthma control PROM data.

Twenty-five $(48 \%)$ of the included studies collected both HRQoL and asthma control questionnaires. Thirteen (34.2\%) studies collected asthma control PROM data but not data from an asthma HRQoL questionnaire, and 8 (15\%) studies collected data using a HRQoL questionnaire but not an asthma control PROM.

\section{Discussion}

This paper provides a review of all published RCTs of biologics, fevipiprant and bronchial thermoplasty for severe asthma up to 2020 . Of these studies, $63 \%$ included a HRQoL measure and $37 \%$ did not. The majority of studies that used a HRQoL measure reported these data in the main paper and not the supplementary material of the reviewed papers ( $99 \%$ vs $1 \%$ ). Fifty-two percent of the studies that reported HRQoL in the main paper also provided this information in the abstract. The majority of studies (68\%) that provided HRQoL data in the abstract reported a significant change in the HRQoL score rather than a non-significant change ( $88 \%$ vs $12 \%$ ).

Of the studies that reported HRQoL 76\% reported these data as a secondary outcome, $2 \%$ as an exploratory outcome; only $18 \%$ reported it as a primary outcome. This finding is consistent with the appraisal from 2011 that recommended that the available questionnaires be considered supplementary rather than core outcomes. ${ }^{23}$

In the present review, the most frequently used HRQoL questionnaire was the Asthma Quality of Life Questionnaire (AQLQ), which was reported in $45 \%$ of the studies that included a HRQoL questionnaire as an outcome, whereas $55 \%$ used a variety of other asthma HRQoL questionnaires, predominantly the AQLQ (S) or AQLQ +12. The data reported here provide areas for future investigation.

First, the LWAQ and the Sydney-AQLQ are examples of asthma HRQoL questionnaires that had their validation papers published at a similar time to the AQLQ (1991 and 1992 vs 1993), ${ }^{11,25,26}$ but were not used as outcomes in any of the included studies. This is despite the evidence that the LWAQ or Sydney-AQLQ may better represent the concerns of patients. ${ }^{24}$ The reasons for the adoption of the AQLQ over the LWAQ or Sydney-AQLQ at the time of their validation could be explored.

Furthermore, there is a delay of approximately 10 years between a HRQoL questionnaire being validated and being used as an outcome in one of the included studies. This is demonstrated by the AQLQ(S) and AQLQ +12 whose validation papers were published in $1999^{31}$ and $2005,{ }^{32}$ but did not have their data reported in any of the included RCTs until 2011 and 2018, respectively.

Our findings also indicate some small fluctuations in the percentage of studies that included a HRQoL questionnaire as an outcome over time. This suggests that the growing criticisms of the available asthma HRQoL questionnaires published from 2012 onwards have had little 
impact on researchers' willingness to include a HRQoL questionnaire in their RCTs.

These topics concern the clinical research community's perceptions and preferences towards the available HRQoL questionnaires. The wider questions here are whether choice of HRQoL outcome measure is determined by, for example, precedent set by large trial centres, preferences of centre leads or guidance from industry. Further investigation of these drivers could enable the selection of more patient centred outcomes.

Very few of the included studies that reported a HRQoL questionnaire reported its subscale scores $(30 \%)$. The subscales of the AQLQ, its variants ${ }^{11,32}$ and the $\mathrm{SGRQ}^{33}$ have been found to be sensitive to change over time, as well as having varying sensitivity to asthma symptoms and emotional impact. ${ }^{34}$ The subscale scores can provide greater information on the specific dimension of HRQoL that has improved from the patient's perspective. The studies that have not reported these data represent missed opportunities to explore, in detail, any improvement in HRQoL following treatment.

When a HRQoL measure was used, the quality of reporting of HRQoL data was generally high, but with some noticeable differences in the fullness of the reporting of the data between studies. Seventy-three percent of the studies that included a HRQoL measure reported the mean HRQoL score pre and post intervention, its distribution and a test of significance. However, the remaining $27 \%$ failed to report to this high standard in concordance with the CONSORT recommendations for reporting trials. ${ }^{35}$ The majority of studies $(76 \%)$ that reported a test of significance found a significant result, and significant results are more likely to be published over non-significant ones. ${ }^{30}$ It is possible that more studies have collected HRQoL questionnaires, but have not been published due to non-significant findings.

A greater proportion of studies included a questionnaire of asthma control than of asthma HRQoL ( $78 \%$ vs $63 \%)$ and $34.2 \%$ of studies collected an asthma control questionnaire but not an asthma HRQoL questionnaire. However, $48 \%$ of the studies collected both a HRQoL and an asthma control questionnaire. Asthma control questionnaires are more closely correlated to the objective clinical goals of improving lung function and reducing exacerbations compared to HRQoL questionnaires, which could explain why asthma control questionnaires feature in a greater proportion of the included studies. However, because asthma control questionnaires are more closely related to objective measures, ${ }^{13}$ they are less likely to capture the full range of a patient's experience. By including an asthma HRQoL questionnaire as well as an asthma control questionnaire as an outcome measure, additional information can be gained from participants while also representing the patient perspective.

\section{Limitations}

This study reviewed only published RCTs in English. We also did not include observational studies or conference abstracts. We observed that some of the published full texts reported that the "AQLQ" had been used when the study's protocol specified either the AQLQ(S) or AQLQ +12 . The protocol could not be located for $21 \%$ of the included studies and it was not possible to check the version of the AQLQ that had been used.

\section{Conclusion}

When HRQoL was used as an outcome, the quality of reporting was of a high standard as the majority of the included studies provided the necessary information to permit accurate interpretation of the HRQoL data. The HRQoL questionnaire was a secondary outcome in the majority of cases. When HRQoL was included, $70 \%$ of the trials did not report the questionnaire subscales which limits the information the HRQoL questionnaire can provide. Of concern however, over a third $(37 \%)$ of the studies did not include a HRQoL questionnaire and this proportion has remained approximately the same from 2001 to 2020.

We recommend further investigation into what determines the choice and the adoption of new HRQoL outcome measures. Advocacy for the use of HRQoL questionnaires by SHARP and other groups would be helped if the barriers to the use of these questionnaires were better understood and overcome. At present, the patients' perspective is under-represented in clinical trials for severe asthma.

\section{Abbreviations}

PRISMA, Preferred Reporting Items for Systematic reviews and Meta-Analysis; NICE, National Institute for Clinical and Health Care Excellence; ERS/ATS, The European Respiratory Society/American Thoracic Society; PROMs, Patient Reported Outcome Measures; HRQoL, Health Related Quality of Life; SHARP, Severe Heterogeneous Asthma Research collaboration, Patientcentred; RCTs, Randomised controlled trials; AQLQ, Asthma Quality of Life Questionnaire; ACQ, Asthma 
Control Questionnaire; ACT, Asthma Control Test; SGRQ, St George's Respiratory Questionnaire.

\section{Data Sharing Statement}

Full data set is available on request from the authors.

\section{Consent for Publication}

All authors give consent for publication in the Journal of Asthma and Allergy.

\section{Acknowledgments}

This report is independent research supported by the National Institute for Health Research Applied Research Collaboration South West Peninsula. The views expressed in this publication are those of the author(s) and not necessarily those of the National Institute for Health Research or the Department of Health and Social Care.

\section{Author Contributions}

All authors made substantial contributions to conception and design, acquisition of data, or analysis and interpretation of data; took part in drafting the article or revising it critically for important intellectual content; agreed to submit to the current journal; gave final approval of the version to be published; and agree to be accountable for all aspects of the work.

\section{Funding}

No funding was received to conduct this review.

\section{Disclosure}

Mr. Lanario reports personal fees from Novartis, outside the submitted work and reports royalties paid to him and University of Plymouth for being a co-author of the pending patent for "Severe Asthma Questionnaire". The authors report no other conflicts of interest in this work.

\section{References}

1. Holguin F, Cardet JC, Chung KF, et al. Management of severe asthma: a European Respiratory Society/American Thoracic Society guideline. Eur Respir J. 2020;2:55.

2. O'Neill S, Sweeney J, Patterson CC, et al. The cost of treating severe refractory asthma in the UK: an economic analysis from the British Thoracic Society Difficult Asthma Registry. Thorax. 2015;70:376-378. doi:10.1136/thoraxjnl-2013-204114

3. Sweeney J, Patterson CC, Menzies-Gow A, et al. British thoracic society difficult asthma n: comorbidity in severe asthma requiring systemic corticosteroid therapy: cross-sectional data from the optimum patient care research database and the British thoracic difficult asthma registry. Thorax. 2016;71:339-346. doi:10.1136/thoraxjnl-2015-207630
4. von Bülow A, Kriegbaum M, Backer V, Porsbjerg C. The prevalence of severe asthma and low asthma control among Danish adults. J Allergy Clin Immunol. 2014;2:759-767. e752.

5. Clark VL, Gibson PG, McDonald VM. What matters to people with severe asthma? Exploring add-on asthma medication and outcomes of importance. ERJ Open Res. 2020;7:254.

6. Foster JM, McDonald VM, Guo M, Reddel HK. "I have lost in every facet of my life": the hidden burden of severe asthma. Eur Respir J. 2017;1:50.

7. Price DB, Trudo F, Voorham J, Xu X, Kerkhof M. Adverse outcomes from initiation of systemic corticosteroids for asthma: long-term observational study. $J$ Asthma Allergy. 2018;11:193-204. doi:10.2147/JAA.S176026

8. Prince M, Patel V, Saxena S, et al. No health without mental health. Lancet. 2007;370:859-877.

9. Djukanovic R, Adcock IM, Anderson G, et al. The Severe Heterogeneous Asthma Research collaboration, Patient-centred (SHARP) ERS Clinical Research Collaboration: a new dawn in asthma research. Eur Respir J. 2018;52:1801671. doi:10.1183/ 13993003.01671-2018

10. Hyland ME, Whalley B, Jones RC, Masoli M. A qualitative study of the impact of severe asthma and its treatment showing that treatment burden is neglected in existing asthma assessment scales. Qual Life Res. 2015;24:631-639. doi:10.1007/s11136-014-0801-x

11. Juniper EF, Guyatt GH, Ferrie PJ, Griffith LE. Measuring quality of life in asthma. Am Rev Respir Dis. 1993;147:832-838. doi:10.1164/ ajrccm/147.4.832

12. Pickles K, Eassey D, Reddel HK, Locock L, Kirkpatrick S, Smith L. "This illness diminishes me. What it does is like theft": a qualitative meta-synthesis of people's experiences of living with asthma. Health Expect. 2018;21:23-40. doi:10.1111/hex.12605

13. Thamrin C, Nydegger R, Stern G, et al. Associations between fluctuations in lung function and asthma control in two populations with differing asthma severity. Thorax. 2011;66:1036-1042. doi:10.1136/ thx.2010.156489

14. Juniper EF, O’Byrne PM, Guyatt GH, Ferrie PJ, King DR. Development and validation of a questionnaire to measure asthma control. Eur Respir J. 1999;14:902-907. doi:10.1034/j.1399-3003.1999.14d29.x

15. Rosenzweig JRC, Edwards L, Lincourt W, Dorinsky P, ZuWallack RL. The relationship between health-related quality of life, lung function and daily symptoms in patients with persistent asthma. Respir Med. 2004;98:1157-1165. doi:10.1016/j. rmed.2004.04.001

16. National Institute for Health and Care Excellence. Omalizumab for treating severe persistent allergic asthma. TA278. April 2013. Available from: https://www.nice.org.uk/ guidance/ta278. Accessed August 04, 2021.

17. National Institute for Health and Care Excellence. Mepolizumab for treating severe refractory eosinophilic asthma. TA431. January 2017. Available from: https://www.nice.org. uk/guidance/ta431. Accessed August 04, 2021.

18. National Institute for Health and Care Excellence. Reslizumab for treating severe eosinophilic asthma. TA479. October 2017. Available from: https://www.nice.org.uk/ guidance/ta479. Accessed August 04, 2021.

19. National Institute for Health and Care Excellence. Benralizumab for treating severe eosinophilic asthma. TA565. March 2019 (updated September 2019). Available from: https://www.nice.org.uk/guidance/ ta565. Accessed August 04, 2021.

20. National Institute for Health and Care Excellence. Bronchial thermoplasty for severe asthma. Interventional procedures guidance. IPG635. December 2018. Available from: https://www.nice.org.uk/ guidance/ipg635. Accessed August 04, 2021.

21. Whalley D, Globe G, Crawford R, et al. Is the EQ-5D fit for purpose in asthma? Acceptability and content validity from the patient perspective. Health Qual Life Outcomes. 2018;16:1-14. doi:10.1186/s12955-018-0970-3 
22. Kontodimopoulos N, Stamatopoulou E, Brinia A, Talias MA, Ferreira LN. Are condition-specific utilities more valid than generic preference-based ones in asthma? Evidence from a study comparing EQ-5D-3L and SF-6D with AQL-5D. Expert Rev Pharmacoecon Outcomes Res. 2018;18:667-675. doi:10.1080/14737167.2018. 1505506

23. Wilson SR, Rand CS, Cabana MD, et al. Asthma outcomes: quality of life. J Allergy Clin Immunol. 2012;129:S88-S123. doi:10.1016/j. jaci.2011.12.988

24. Apfelbacher CJ, Jones CJ, Frew A, Smith H. Validity of three asthma-specific quality of life questionnaires: the patients' perspective. BMJ Open. 2016;1:6.

25. Hyland M. The living with asthma questionnaire. Respir Med. 1991;85:13-16. doi:10.1016/S0954-6111(06)80163-0

26. Marks GB, Dunn SM, Woolcock AJ. A scale for the measurement of quality of life in adults with asthma. $J$ Clin Epidemiol. 1992;45:461-472. doi:10.1016/0895-4356(92)90095-5

27. Hamaker M, Schulkes K, Ten Bokkel Huinink D, van Munster B, van Huis L, van den Bos F. Evaluation and reporting of quality of life outcomes in Phase III chemotherapy trials for poor prognosis malignancies. Quality Life Res. 2017;26(1):65-71. doi:10.1007/ s11136-016-1360-0

28. Schandelmaier S, Conen K, Von Elm E, et al. Planning and reporting of quality-of-life outcomes in cancer trials. Ann Oncol. 2015;26:1966-1973. doi:10.1093/annonc/mdv283

29. Scottish Intercollegiate Guidelines Network [document online]. Randomised controlled trials search filter. Available from:https:// www.sign.ac.uk/what-we-do/methodology/search-filters/. Accessed September 19, 2019.

30. Hopewell S, Loudon K, Clarke MJ, Oxman AD, Dickersin K. Publication bias in clinical trials due to statistical significance or direction of trial results. Cochrane Database Sys Rev. 2009;2010(1). doi:10.1002/14651858.MR000006.pub3

31. Juniper EF, Buist AS, Cox FM, Ferrie PJ, King DR. Validation of a standardized version of the asthma quality of life questionnaire. Chest. 1999;115:1265-1270. doi:10.1378/chest.115.5.1265

32. Juniper EF, Svensson K, Mork AC, Stahl E. Modification of the asthma quality of life questionnaire (standardised) for patients 12 years and older. Health Qual Life Outcomes. 2005;3:58. doi:10.1186/1477-7525-3-58

33. Jones PW, Quirk FH, Baveystock CM, Littlejohns P, Self-complete A. Measure of Health status for chronic airflow limitation: the St. George's respiratory questionnaire. Am Rev Respir Dis. 1992;145:1321-1327. doi:10.1164/ajrccm/145.6.1321

34. Sanjuás C, Alonso J, Prieto L, Ferrer M, Broquetas JM, Antó JM. Health-related quality of life in asthma: a comparison between the St george's respiratory questionnaire and the asthma quality of life questionnaire. Quality Life Res. 2002;11:729-738. doi:10.1023/ A: 1020897816228

35. Antes G. The New CONSORT Statement. British Medical Journal Publishing Group; 2010.

36. Austin CD, Gonzalez Edick M, Ferrando RE, et al. A randomized, placebo-controlled trial evaluating effects of lebrikizumab on airway eosinophilic inflammation and remodelling in uncontrolled asthma (CLAVIER). Clin Exp Allergy. 2020;50:1342-1351. doi:10.1111/ cea. 13731

37. Ayars AG, Altman LC, Potter-Perigo S, Radford K, Wight TN, Nair P. Sputum hyaluronan and versican in severe eosinophilic asthma. Int Arch Allergy Immunol. 2013;161:65-73. doi:10.1159/ 000343031

38. Ayres JG, Higgins B, Chilvers ER, Ayre G, Blogg M, Fox H. Efficacy and tolerability of anti-immunoglobulin $\mathrm{E}$ therapy with omalizumab in patients with poorly controlled (moderate-to-severe) allergic asthma. Eur $J$ Allergy Clin Immunol. 2004;59:701-708. doi:10.1111/j.1398-9995.2004.00533.x
39. Bel EH, Wenzel SE, Thompson PJ, et al. Oral glucocorticoid-sparing effect of mepolizumab in eosinophilic asthma. $N$ Eng $J$ Med. 2014;371:1189-1197. doi:10.1056/NEJMoa1403291

40. Bernstein JA, Virchow JC, Murphy K, et al. Effect of fixed-dose subcutaneous reslizumab on asthma exacerbations in patients with severe uncontrolled asthma and corticosteroid sparing in patients with oral corticosteroid-dependent asthma: results from two Phase 3, randomised, double-blind, placebo-controlled trials. Lancet Respi Med. 2020;8:461-474.

41. Bjermer L, Lemiere C, Maspero J, Weiss S, Zangrilli J, Germinaro M. Reslizumab for inadequately controlled asthma with elevated blood eosinophil levels: a randomized phase 3 Study. Chest. 2016;150:789-798. doi:10.1016/j.chest.2016.03.032

42. Bleecker ER, FitzGerald JM, Chanez P, et al. Efficacy and safety of benralizumab for patients with severe asthma uncontrolled with high-dosage inhaled corticosteroids and long-acting beta2-agonists (SIROCCO): a randomised, multicentre, placebo-controlled phase 3 trial. Lancet. 2016;388:2115-2127. doi:10.1016/S0140-6736(16)31324-1

43. Bousquet J, Siergiejko Z, Swiebocka E, et al. Persistency of response to omalizumab therapy in severe allergic (IgE-mediated) asthma. Eur $J$ Allergy Clin Immunol. 2011;66:671-678. doi:10.1111/j.13989995.2010.02522.x

44. Brightling CE, Chanez P, Leigh R, et al. Efficacy and safety of tralokinumab in patients with severe uncontrolled asthma: a randomised, double-blind, placebo-controlled, Phase 2b trial. Lancet Respi Med. 2015;3:692-701. doi:10.1016/S2213-2600(15)00197-6

45. Brightling CE, Gaga M, Inoue H, et al. Effectiveness of fevipiprant in reducing exacerbations in patients with severe asthma (LUSTER-1 and LUSTER-2): two phase 3 randomised controlled trials. Lancet Respi Med. 2021;9:43-56. doi:10.1016/S2213-2600(20)30412-4

46. Buhl R, Hanf G, Soler M, et al. The anti-IgE antibody omalizumab improves asthma-related quality of life in patients with allergic asthma. Eur Respir J. 2002;20:1088-1094. doi:10.1183/09031936.02.00016502

47. Buhl R, Soler M, Matz J, et al. Omalizumab provides long-term control in patients with moderate-to-severe allergic asthma. Eur Respir J. 2002;20:73-78. doi:10.1183/09031936.02.00278102

48. Busse W, Corren J, Lanier BQ, et al. Omalizumab, anti-IgE recombinant humanized monoclonal antibody, for the treatment of severe allergic asthma. J Allergy Clin Immunol. 2001;108:184-190. doi:10.1067/mai.2001.117880

49. Busse WW, Bleecker ER, FitzGerald JM, et al. Long-term safety and efficacy of benralizumab in patients with severe, uncontrolled asthma: 1 -year results from the BORA phase 3 extension trial. Lancet Respi Med. 2019;7:46-59. doi:10.1016/S2213-2600(18)30406-5

50. Busse WW, Brusselle GG, Korn S, et al. Tralokinumab did not demonstrate oral corticosteroid-sparing effects in severe asthma. Eur Respir J. 2019;2:53.

51. Castro M, Rubin AS, Laviolette M, et al. Effectiveness and safety of bronchial thermoplasty in the treatment of severe asthma: a multicenter, randomized, double-blind, sham-controlled clinical trial. Am J Respir Crit Care Med. 2010;181:116-124. doi:10.1164/rccm.200903-0354OC

52. Castro M, Mathur S, Hargreave F, et al. Reslizumab for poorly controlled, eosinophilic asthma: a randomized, placebo-controlled study. Am J Respir Crit Care Med. 2011;184:1125-1132. doi:10.1164/rccm.201103-0396OC

53. Castro M, Wenzel SE, Bleecker ER, et al. Benralizumab, an antiinterleukin 5 receptor $\alpha$ monoclonal antibody, versus placebo for uncontrolled eosinophilic asthma: a phase $2 \mathrm{~b}$ randomised dose-ranging study. Lancet Respi Med. 2014;2:879-890. doi:10.1016/S2213-2600(14) 70201-2

54. Castro M, Zangrilli J, Wechsler ME, et al. Reslizumab for inadequately controlled asthma with elevated blood eosinophil counts: results from two multicentre, parallel, double-blind, randomised, placebo-controlled, phase 3 trials. Lancet Respi Med. 2015;3:355-366. doi:10.1016/S2213-2600(15)00042-9 
55. Chanez P, Contin-Bordes C, Garcia G, Verkindre C, Didier A, De Blay F. Omalizumab-induced decrease of FceRI expression in patients with severe allergic asthma. Respir Med. 2010;104:1608-1617. doi:10.1016/j.rmed.2010.07.011

56. Chupp GL, Bradford ES, Albers FC, et al. Efficacy of mepolizumab add-on therapy on health-related quality of life and markers of asthma control in severe eosinophilic asthma (MUSCA): a randomised, double-blind, placebo-controlled, parallel-group, multicentre, phase $3 \mathrm{~b}$ trial. Lancet Respi Med. 2017;5:390-400. doi:10.1016/S2213-2600(17) 30125-X

57. Corren J, Lemanske RF, Hanania NA, et al. Lebrikizumab treatment in adults with asthma. $N$ Eng $J$ Med. 2011;365:1088-1098. doi:10.1056/NEJMoa1106469

58. Corren J, Weinstein S, Janka L, Zangrilli J, Garin M. Phase 3 study of reslizumab in patients with poorly controlled asthma: effects across a broad range of eosinophil counts. Chest. 2016;150:799-810. doi:10.1016/j.chest.2016.03.018

59. Corren J, Parnes JR, Wang L, Mo M, Roseti SL, Griffiths JM. Tezepelumab in adults with uncontrolled asthma. $N$ Eng $J$ Med. 2017;377:936-946. doi:10.1056/NEJMoa1704064

60. Cox G, Thomson NC, Rubin AS, et al. Asthma control during the year after bronchial thermoplasty. $N$ Eng $J$ Med. 2007;356:1327-1337. doi:10.1056/NEJMoa064707

61. Finn A, Gross G, Van Bavel J, et al. Omalizumab improves asthma-related quality of life in patients with severe allergic asthma. J Allergy Clin Immunol. 2003;111:278-284. doi:10.1067/ mai.2003.54

62. FitzGerald JM, Bleecker ER, Nair P, et al. Benralizumab, an anti-interleukin-5 receptor alpha monoclonal antibody, as add-on treatment for patients with severe, uncontrolled, eosinophilic asthma (CALIMA): a randomised, double-blind, placebo-controlled phase 3 trial. Lancet. 2016;388:2128-2141. doi:10.1016/S0140-6736(16)31322-8

63. Garcia G, Magnan A, Chiron R, et al. A proof-of-concept, randomized, controlled trial of omalizumab in patients with severe, difficult-to-control, nonatopic asthma. Chest. 2013;144:411-419. doi:10.1378/chest.12-1961

64. Gonem S, Berair R, Singapuri A, et al. Fevipiprant, a prostaglandin D2 receptor 2 antagonist, in patients with persistent eosinophilic asthma: a single-centre, randomised, double-blind, parallel-group, placebo-controlled trial. Lancet Respi Med. 2016;4:699-707. doi:10.1016/S2213-2600(16)30179-5

65. Goorsenberg AWM, Hooghe JNS, Srikanthan K, et al. Bronchial Thermoplasty induced airway smooth muscle reduction and clinical response in severe asthma: the TASMA randomized trial. Am J Respir Crit Care Med. 2020;203(2):175.

66. Gottlow M, Svensson DJ, Lipkovich I, et al. Application of structured statistical analyses to identify a biomarker predictive of enhanced tralokinumab efficacy in phase III clinical trials for severe, uncontrolled asthma. BMC Pulm Med. 2019;19:129. doi:10.1186/s12890019-0889-4

67. Haldar P, Brightling CE, Hargadon B, et al. Mepolizumab and exacerbations of refractory eosinophilic asthma. $N$ Eng $\mathrm{J} \mathrm{Med.}$ 2009;360:973-984. doi:10.1056/NEJMoa0808991

68. Hall CS, Quirk JD, Goss CW, et al. Single-session bronchial thermoplasty guided by $129 \mathrm{Xe}$ Magnetic Resonance Imaging. A pilot randomized controlled clinical trial. Am J Respir Crit Care Med. 2020;202:524-534. doi:10.1164/rccm.201905-10210C

69. Hanania NA, Alpan O, Hamilos DL, et al. Omalizumab in severe allergic asthma inadequately controlled with standard therapy: a randomized trial. Ann Intern Med. 2011;154:573-582. doi:10.7326/0003-4819-154-9-201105030-00002

70. Holgate ST, Chuchalin AG, Hebert J, et al. Efficacy and safety of a recombinant anti-immunoglobulin $\mathrm{E}$ antibody (omalizumab) in severe allergic asthma. Clin Exp Allergy. 2004;34:632-638. doi:10.1111/j.1365-2222.2004.1916.x
71. Hoshino M, Ohtawa J. Effects of adding omalizumab, an anti-immunoglobulin $\mathrm{E}$ antibody, on airway wall thickening in asthma. Respiration. 2012;83:520-528. doi:10.1159/000334701

72. Humbert M, Beasley R, Ayres J, et al. Benefits of omalizumab as add-on therapy in patients with severe persistent asthma who are inadequately controlled despite best available therapy (GINA 2002 step 4 treatment): INNOVATE. Eur J Allergy Clin Immunol. 2005;60:309-316. doi:10.1111/j.1398-9995.2004.00772.x

73. Lanier BQ, Corren J, Lumry W, Liu J, Fowler-Taylor A, Gupta N. Omalizumab is effective in the long-term control of severe allergic asthma. Ann Allergy Asthma Immunol. 2003;91:154-159. doi:10.1016/S1081-1206(10)62170-9

74. Ledford D, Busse W, Trzaskoma B, et al. A randomized multicenter study evaluating Xolair persistence of response after long-term therapy. J Allergy Clin Immunol. 2017;140:162. doi:10.1016/j. jaci.2016.08.054

75. Li J, Kang J, Wang C, et al. Omalizumab improves quality of life and asthma control in Chinese patients with moderate to severe asthma: a randomized phase III study. Allergy Asthma Immunol Res. 2016;8:319-328. doi:10.4168/aair.2016.8.4.319

76. Mukherjee M, Kjarsgaard M, Radford K, et al. Omalizumab in patients with severe asthma and persistent sputum eosinophilia. Allergy Asthma Clin Immunol. 2019;15:21. doi:10.1186/s13223019-0337-2

77. Nair P, Wenzel S, Rabe KF, et al. Oral glucocorticoid-sparing effect of benralizumab in severe asthma. $N$ Eng $J$ Med. 2017;376:2448-2458. doi:10.1056/NEJMoa1703501

78. Ohta K, Miyamoto T, Amagasaki T, Yamamoto M. Efficacy and safety of omalizumab in an Asian population with moderate-tosevere persistent asthma. Respirology. 2009;14:1156-1165. doi:10.1111/j.1440-1843.2009.01633.x

79. Ohta K, Adachi M, Tohda Y, et al. Efficacy and safety of benralizumab in Japanese patients with severe, uncontrolled eosinophilic asthma. Allergol Int. 2018;67:266-272. doi:10.1016/j.alit.2017.10.004

80. Ortega HG, Liu MC, Pavord ID, et al. Mepolizumab treatment in patients with severe eosinophilic asthma. $N$ Eng $J$ Med. 2014;371:1198-1207. doi:10.1056/NEJMoa1403290

81. Panettieri RA, Sjobring U, Peterffy A, et al. Tralokinumab for severe, uncontrolled asthma (STRATOS 1 and STRATOS 2): two randomised, double-blind, placebo-controlled, phase 3 clinical trials. Lancet Respi Med. 2018;6:511-525. doi:10.1016/S2213-2600(18) 30184-X

82. Panettieri RA, Welte T, Shenoy KV, et al. Onset of effect, changes in airflow obstruction and lung volume, and health-related quality of life improvements with benralizumab for patients with severe eosinophilic asthma: phase iiib randomized, controlled trial (SOLANA). $J$ Asthma Allergy. 2020;13:115-126. doi:10.2147/JAA.S240044

83. Pasha MA, Jourd'Heuil D, Jourd'Heuil F, et al. The effect of omalizumab on small airway inflammation as measured by exhaled nitric oxide in moderate-to-severe asthmatic patients. Allergy Asthma Proce. 2014;35:241-249. doi:10.2500/aap.2014.35.3741

84. Pavord ID, Cox G, Thomson NC, et al. Safety and efficacy of bronchial thermoplasty in symptomatic, severe asthma. Am J Respir Crit Care Med. 2007;176:1185-1191. doi:10.1164/rccm.200704-571OC

85. Pavord ID, Korn S, Howarth P, et al. Mepolizumab for severe eosinophilic asthma (DREAM): a multicentre, double-blind, placebo-controlled trial. Lancet. 2012;380:651-659. doi:10.1016/ S0140-6736(12)60988-X

86. Piper E, Brightling C, Niven R, et al. A Phase II placebo-controlled study of tralokinumab in moderate-to-severe asthma. Eur Respir J. 2013;41:330-338. doi:10.1183/09031936.00223411

87. Rubin AS, Souza-Machado A, Andradre-Lima M, Ferreira F, Honda A, Matozo TM. Effect of omalizumab as add-on therapy on asthma-related quality of life in severe allergic asthma: a Brazilian study (QUALITX). J Asthma. 2012;49:288-293. doi:10.3109/ 02770903.2012.660297 
88. Russell RJ, Chachi L, FitzGerald JM, et al. Effect of tralokinumab, an interleukin-13 neutralising monoclonal antibody, on eosinophilic airway inflammation in uncontrolled moderate-to-severe asthma (MESOS): a multicentre, double-blind, randomised, placebo-controlled phase 2 trial. Lancet Respi Med. 2018;6:499-510. doi:10.1016/S2213-2600(18) 30201-7

89. Sakamoto K, Matsuki S, Irie S, et al. Randomized, placebo-controlled study to evaluate the safety, tolerability, pharmacokinetics, and immunogenicity of subcutaneous tezepelumab in healthy Japanese men. Clin Pharmacol Drug Dev. 2020;9:833-840. doi:10.1002/cpdd.775

90. Soler M, Matz J, Townley R, et al. The anti-IgE antibody omalizumab reduces exacerbations and steroid requirement in allergic asthmatics. Eur Respir J. 2001;18:254-261. doi:10.1183/09031936.01.00092101

91. Sthoeger ZM, Eliraz A, Asher I, Berkman N, Elbirt D. The beneficial effects of Xolair (Omalizumab) as add-on therapy in patients with severe persistent asthma who are inadequately controlled despite best available treatment (GINA 2002 step IV - The Israeli arm of the INNOVATE study. Israel Med Assoc J. 2007;9:472-475.
92. Vignola AM, Humbert M, Bousquet J, et al. Efficacy and tolerability of anti-immunoglobulin E therapy with omalizumab in patients with concomitant allergic asthma and persistent allergic rhinitis: SOLAR. Eur J Allergy Clin Immunol. 2004;59:709-717. doi:10.1111/j.1398-9995.2004.00550.x

93. Zeitlin PL, Leong M, Cole J, et al. Benralizumab does not impair antibody response to seasonal influenza vaccination in adolescent and young adult patients with moderate to severe asthma: results from the phase iiib ALIZE trial. $J$ Asthma Allergy. 2018;11:181-192. doi:10.2147/JAA.S172338

\section{Publish your work in this journal}

The Journal of Asthma and Allergy is an international, peer-reviewed open-access journal publishing original research, reports, editorials and commentaries on the following topics: Asthma; Pulmonary physiology; Asthma related clinical health; Clinical immunology and the immunological basis of disease; Pharmacological interventions and new therapies. The manuscript management system is completely online and includes a very quick and fair peer-review system, which is all easy to use. Visit http://www.dovepress.com/testimonials.php to read real quotes from published authors. 